This article has been accepted for publication in a future issue of this conference proceeidngs, but has not been fully edited. Content may change prior to final publication. Citation information: DOI10.1109/CPE-POWERENG50821.2021.9501197, 2021 IEEE 15th International Conference on Compatibility, Power Electronics and Power Engineering (CPE-POWERENG)

\title{
Operational Challenges to Accommodate High Penetration of Electric Vehicles: A Comparison between UK and China
}

\author{
Chun Sing Lai \\ Brunel Interdisciplinary Power Systems \\ Research Centre \\ Brunel University London \\ London, UK \\ chunsing.lai@brunel.ac.uk
}

Gareth A. Taylor

Brunel Interdisciplinary Power Systems Research Centre

Brunel University London

London, UK

gareth.taylor@brunel.ac.uk

\author{
Dashen Chen \\ Department of Electrical Engineering \\ Guangdong University of Technology \\ Guangzhou, China \\ 2112004023@mail2.gdut.edu.cn
}

Ioana Pisica

\author{
Brunel Interdisciplinary Power Systems \\ Research Centre \\ Brunel University London \\ London, UK \\ ioana.pisica@brunel.ac.uk
}

\author{
$\mathrm{Xu} \mathrm{Xu}$ \\ School of Electrical and Electronic \\ Engineering \\ Nanyang Technological University \\ Jurong West, Singapore \\ xu.xu@ntu.edu.sg \\ Loi Lei Lai \\ Department of Electrical Engineering \\ Guangdong University of Technology \\ Guangzhou, China \\ 1.1.1ai@ieee.org
}

\begin{abstract}
Electric vehicles (EVs) play a key role in transport electrification and decarbonizing the society. EVs are becoming popular due to the advancement of drivetrain and battery technologies, with the support from plummeting costs. However, many countries are facing with challenges to accommodate large-scale adoption of electric vehicles due to the great amount of electricity required from the grid for charging. Current research focuses on developing incentives and tariff structure to encourage EV drivers to charge and discharge at appropriate times. However, relying on driver's behavior can be a risky decision for network operators. A regional high electricity demand at a short instance can cause severe technical challenges for the distribution network, including thermal and voltage limit violations. This paper presents and compares the EV development for the UK and China. A research agenda is proposed to consider how largescale energy storage would benefit the distribution network for rapid charging of electric vehicles.
\end{abstract}

Keywords-Large-scale energy storage, electric vehicle, distribution network, electric vehicle charging station

\section{INTRODUCTION}

To reduce global carbon emissions, there is a growing need of electric vehicles (EVs) powered by renewables including solar, wind, and other forms of low-carbon energy sources. Several research projects were conducted to integrate EVs into the society. Ref. [1] proposed an intelligent charging technology for EVs and used fuzzy logic controller to control and manage EV charging. The controller adjusts and controls EV charging according to the electricity price signal provided by the power company and EV battery charging state. This would allow electric car users to charge their cars at low cost, while keeping the distribution network running. In Ref. [2], agent-based modeling method was proposed to predict the charging demands of different types of electric vehicles. The function of the system is not determined by design, but by the agents in the environment. Ref. [3] presented an optimal coordinated unit combination model for wind power generation and EV charging loads. The results suggest that the energy thrown away by wind power could also reduce the cost of charging EVs. However, the model works by scheduling the EV's charging and discharging behavior, which relies heavily on the cooperation of the EV owner. This will bring risks to the operation of the power system. Ref. [4] presented the use of photovoltaic (PV) system and energy storage system to minimize the charging cost of EVs and reduce the impact of PV uncertainty on the power grid. But this strategy of using EVs to coordinate with grid dispatching can be inconvenient for EV users. Ref. [5] proposed to use grid-to-vehicle $(\mathrm{G} 2 \mathrm{~V})$ and vehicle-to-grid (V2G) scheduling strategies to solve grid congestion caused by large-scale EV charging. Charging costs can be minimized from technical and financial considerations.

The global sales of EVs are increasing annually as shown in Fig. 1 [6].

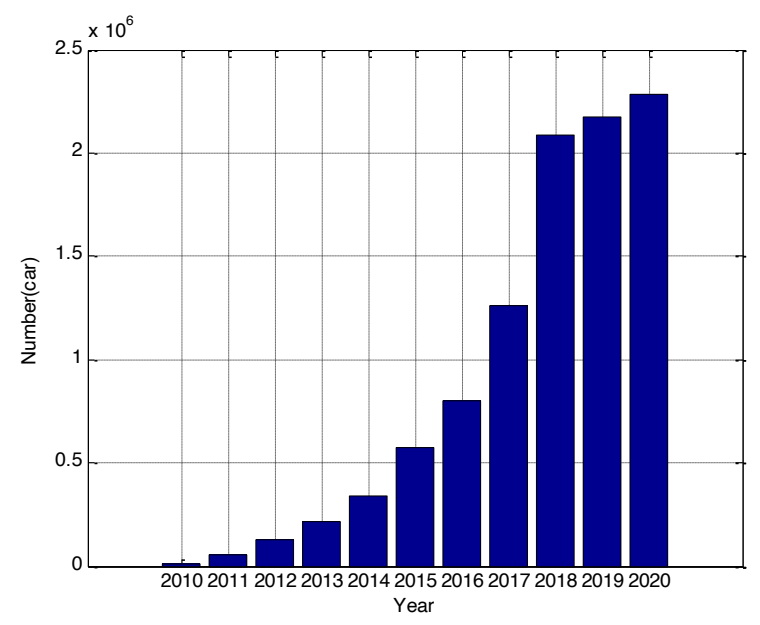

Fig. 1 Global EV sales from 2010 to 2020

With abundant data becoming readily available, datadriven techniques can be used to optimize the power flows in a distribution network. This paper aims to describe the operational challenges to accommodate high penetration of EVs and examine a data-driven framework to address the operational challenges. In particular, this paper examines the EV development in China and the UK, where there are significant differences including geographical area and electricity infrastructure. The rest of this paper is organized as follows: Section II presents the governmental policies for electric vehicles in China and the UK. Measures taken by 
This article has been accepted for publication in a future issue of this conference proceeidngs, but has not been fully edited. Content may change prior to final publication. Citation information: DOI10.1109/CPE-POWERENG50821.2021.9501197, 2021 IEEE 15th International Conference on Compatibility, Power Electronics and Power Engineering (CPE-POWERENG)

the two countries to manage the EV charging problem are described. Section III describes the relevant projects in EV studies. Section IV presents a data-driven framework for managing the charging demand for EVs with large-scale battery. The conclusion is provided in Section V.

\section{EVS CHARGING IN THE TWO COUNTRIES}

This section presents an overview of EV development in China and the UK.

\section{A. China}

In 2016, China imported 380 million tons of oil, making it the world's largest oil importer [7], EVs are important for reducing oil demand and pollution emissions. China has put forward many policies to promote the development of EVs including research support for the "863" major project on EVs, promotion of the "1,000 vehicles in 10 cities" demonstration project, and subsidies for the purchase of new energy vehicles [8]. In 2020, China Southern Grid Electric Vehicle Service Co., Ltd. and Tsinghua University's Sichuan Energy Internet Research Institute signed a cooperation agreement in Chengdu's Tianfu New Area [9]. The two sides had in-depth exchanges on distributed resource intelligent regulation and convergent trading, dynamic intelligent planning of charging and changing power network. Fig. 2 shows that the EV sales are also growing in China [6], contributed by the government support [10]. It is noticed that the sales in 2019 is less than 2018, this may be contributed by the COVID pandemic, where vehicle demand is reduced due to travel restrictions or the source of data for the year is incomplete.

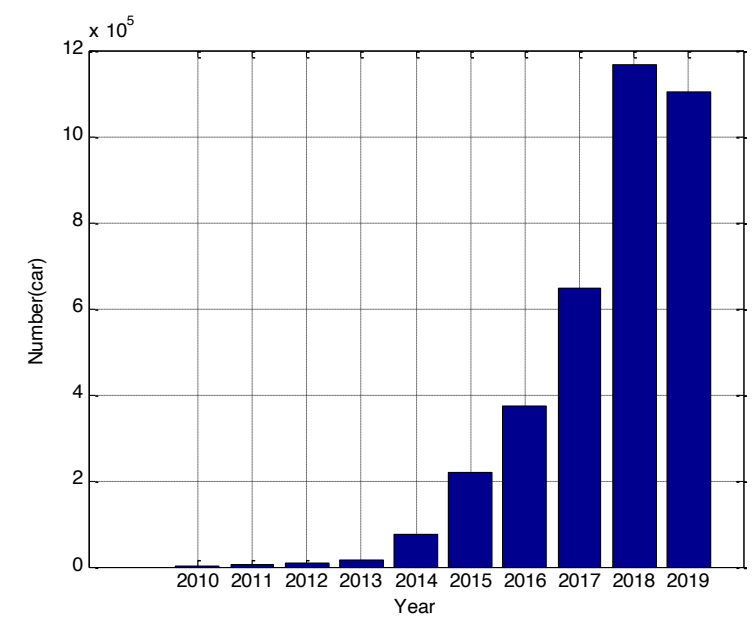

Fig. 2 China's electric vehicle sales from 2010 to 2019

As the number of EVs grows rapidly, how to charge them becomes a problem. In China, the government has promoted the development of EVs by not only subsidizing buyers of EVs [9], but also waiving capacity charges for charging piles [9]. China aims to build a unified charging network across the country. By the end of 2017, the State Grid Corporation of China (State Grid) had built a highspeed intercity fast charging network with nine vertical and nine horizontal rings, with an average distance of less than $50 \mathrm{~km}$ between stations. Connecting urban stations through highway charging stations; The Beijing-Hong Kong-Macao Expressway is interconnected with China Southern Power Grid, initially forming a "national network" [11]. State Grid is also actively installing public charging piles and has installed 95,883 charging piles in 2020 [12]. In 2019, China has 301,238 public slow charging piles and 214,670 public fast charging piles [13-14].

\section{B. The UK}

The UK government's policies [15] have spurred an increase in sales of EVs. For EVs bought in the UK that has a range of $70+$ miles and sell for less than $£ 50,000$, consumers can receive a government subsidy of up to $£ 3,000$ [16]. Fig. 3 depicts the EV sales in the UK [17]. Plug-in Hybrid Electric Vehicle. (PHEV) is a vehicle driven by both an internal combustion engine and an electric motor. Battery Electric Vehicle (BEV) is a vehicle powered entirely by batteries and electric motor. Both vehicles are experiencing a growth in sales and BEV may surpass PHEV in demand.

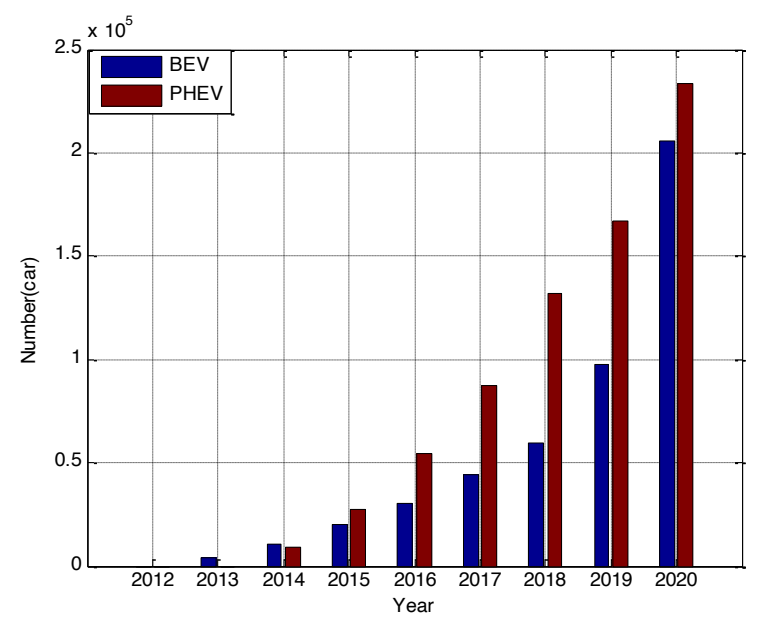

Fig. 3 UK's PHEV and BEV sales from 2012 to 2020

The UK has put forward a series of funding schemes for charging EVs. The government set up the Plugged-In Places (PIPS) scheme in 2010 to match local businesses and public sector consortia to build their own charging points [18]. In 2013, the Office for Low Emission Vehicles (OLEV) launched a $£ 13.5$ million grant scheme to subsidize householders installing equipment at home. In recent years, OLEV has launched three support schemes to install charging facilities at home, workplaces and streets [19]. In UK, EV users can choose their supply operator based the energy price, the charging price of EVs in the UK is shown in Table I [20]. Different electricity suppliers have different electricity prices. Prices are also different for the same provider, depending on the time of day. EV drivers will generally prefer to charge their cars during periods when electricity prices are low. This pricing method allows EVs to be charged in an orderly manner, which can improve the safety of power supply from the distribution network. Encouraged by government policy, there are now 9,447 quick charging piles and 37,429 public charging connectors in the UK [17].

In summary, it is worth comparing the two countries due to the significant differences in electricity markets and power system structure. UK has a mature electricity market with many electricity supplier companies. Users can choose the appropriate electricity supplier according to their own needs. EV users can find the right electricity supplier according to their needs to reduce charging costs. In contrast to China, State Grid dispatches the distribution network in the form of unified dispatching to fully exploit the peak regulation capacity of thermal power and make full use of 
This article has been accepted for publication in a future issue of this conference proceeidngs, but has not been fully edited. Content may change prior to final publication. Citation information: DOI10.1109/CPE-POWERENG50821.2021.9501197, 2021 IEEE 15th International Conference on Compatibility, Power Electronics and Power Engineering (CPE-POWERENG)

pumped storage power stations [21]. This unified scheduling method can better control the power flows and cope with the additional electricity demand brought by large-scale EV charging.

TABLE I.

UK'S EV ENERGY TARIFFS [20]

\begin{tabular}{|c|c|c|c|}
\hline \multirow{2}{*}{$\begin{array}{c}\text { Supply } \\
\text { operator }\end{array}$} & \multicolumn{3}{|c|}{ Charge standard (p/kWh) } \\
\cline { 2 - 4 } Good energy & Standard & Off-peak & Peak \\
\hline EDF & 16.27 & 12.2 & 16.34 \\
\hline OVO energy & 14.34 & 4.5 & 17.81 \\
\hline $\begin{array}{c}\text { Scottish } \\
\text { Power }\end{array}$ & 17.89 & 10.33 & 17.78 \\
\hline Ecotricity & 16.54 & 4.74 & N/A \\
\hline E.On & 19.8 & 10.31 & N/A \\
\hline Shell Energy & 15.5 & 10.44 & 17.19 \\
\hline British Gas & 19.53 & 5.99 & N/A \\
\hline $\begin{array}{c}\text { Octopus } \\
\text { Energy }\end{array}$ & N/A & 5 & N/A \\
\hline
\end{tabular}

\section{THE RELATED WORK}

The penetration of EVs in the distribution network is growing as relevant national policies are developed. Simultaneously, the number of clean energy power generation sources in the distribution network is also increasing. Research projects were conducted to study how $\mathrm{PV}$ and EV penetrations would affect the electricity prices for UK distribution networks [22]. Ref. [22] calculated the annual electricity consumption of EVs by analyzing the total mileage travelled, as provided in Equations (1-3). The comparison was made by changing the permeability of PV and EV. It is determined that the electricity prices are low when the penetrations of EV and PV are high and low, respectively. The addition of PV leads to the reduction of the net electricity purchased by users. In order to achieve the target revenue, electricity suppliers raise the electricity price to achieve the target. Home charging is charged on a twopart tariff. This two-part tariff can be an issue for people who do not have PV installed. To address the aforementioned issue, the three-part tariff is presented which composed of a fixed component, a capacity component $(\mathrm{kW})$ and an energy component $(\mathrm{kWh})$. If the house is not installed with PV, there is no need to pay the cost generated by the energy component. Houses that do not have PV installed will not receive a revenue from the grid by generating electricity.

$$
\begin{aligned}
T R & =F * 365+V * M \\
V & =\frac{R F U R}{A E C}(£ / \mathrm{kWh}) \\
F & =\frac{R F F C}{N O C * 365}(£)
\end{aligned}
$$

$T R(£)$ is the sum of revenues from unit rates and revenues from fixed charges. $R F U R(£)$ is the revenues from unit rates. $R F F C(£)$ is revenues from fixed charges. $A E C$ $(\mathrm{kWh})$ is annual energy consumption. $N O C$ (pcs) is number of customers. $F$ is the fixed portion of the electricity bill and daily cost per customer. $V$ is the price in the electricity bill that is charged according to the amount of electricity used. $M(\mathrm{kWh})$ is the amount of electricity used.

Large-scale EV charging and distributed energy bring great influence on the distribution network. Ref. [23] put forward the method of orderly charging and time-of-use price to guide EV charging. In this way, the influence of EV charging on distribution network is reduced. Ref. [24] indicated that energy storage is a good solution to this problem. It presented a typical operation model of distributed energy storage in distribution network. The economic dispatching mode of distributed energy storage is established, and the economic dispatching strategy of postponing substation expansion is put forward. But its predictions for distributed energy and electric vehicle charging are less accurate. The Smarter Network Storage (SNS) project features a $6 \mathrm{MW} / 10 \mathrm{MWh}$ storage solution comprising approximately 50,000 lithium-ion batteries. This project provides a guarantee for the safety of the distribution network [25]. The project presented a report [25] on energy storage for security of supply and suggested where storage would be most beneficial. Where upgrading the distribution network is particularly expensive, complex and time-consuming, storage is a good place to install it. It is also suitable to install energy storage facilities where there is little time to use capacity after the distribution network has increased. The installation of energy storage equipment will ensure that the distribution network does not need to be upgraded for at least 5 years. The report [25] found that when power shortages did not exceed 30 percent, distribution networks with large-scale storage batteries would still be able to provide safe supplies. Energy storage system needs to predict the maximum power of the next day, energy storage systems can provide power reserves. Because the power grid cannot supply enough power at the peak of electricity consumption, part of the demand cannot be met and the security of power supply cannot be guaranteed. Energy storage system needs to be able to supply power demand and ensure adequate stored energy for backup purposes. Therefore, the energy storage system also needs to predict how much energy it will need to supply next day. The report points out that if there is no error in the forecast and energy storage system are able to reserve enough power and energy, there will be no shortage of power. Suppose the energy storage system predicted exactly how much energy needed to be stored but the energy storage system only stored $50 \%$ of the electricity. This can result in the storage of energy not being able to sustain the power supply when it is needed. Similarly, if the power reserve of the energy storage system does not meet the predicted requirements, and the power supply is insufficient when the power supply is needed, then part of the load cannot be supplied. Generally speaking, there will be errors in the prediction, and partial power shortage will happen when the power error and the energy storage error occur. Therefore, energy storage systems are required to reserve $110 \%$ of the predicted demand, which can well cope with the impact of forecasting errors. The report presented a calculation method for Equivalent Firm Capacity (EFC) which can be obtained by calculating Expected Energy Not Supplied (EENS) (4)-(6). The EENS that arises in a system equipped with an 'always available' network connection of size $\omega$ (MW) can be defined as $E E N S^{\omega}$. The $E F C^{*}$ value corresponding to a particular target $E E N S^{*}$ can be defined as the size of an 'always available' circuit of size $\omega$ that gives rise to the same risk level.

$$
E E N S=\sum_{\forall d, t} U_{d, t}
$$


This article has been accepted for publication in a future issue of this conference proceeidngs, but has not been fully edited. Content may change prior to final publication. Citation information: DOI10.1109/CPE-POWERENG50821.2021.9501197, 2021 IEEE 15th International Conference on Compatibility, Power Electronics and Power Engineering (CPE-POWERENG)

$$
\begin{gathered}
U_{d, t}=D_{d, t}-P_{d, t} \\
E F C^{*}=\operatorname{argmin}\left\{\left(E E N S^{\omega}-E E N S^{*}\right)^{2}\right\}
\end{gathered}
$$

$D_{d, t}(\mathrm{MW})$ is the residual group demand above the network capacity limit at hour $t$ of day $d . P_{d, t}$ is the power discharged by energy storage (MW).

\section{A DATA-DRIVEN FRAMEWORK FOR MANAGING EV CHARGING DEMAND WITH LARGE-SCALE BATTERY}

In this section we will discuss how to use large-scale batteries to deal with EV charging. Large-scale EV charging will lead to problems such as voltage reduction at distribution network nodes, line congestion, line loss increase and transformer overload.

\section{A. The Framework}

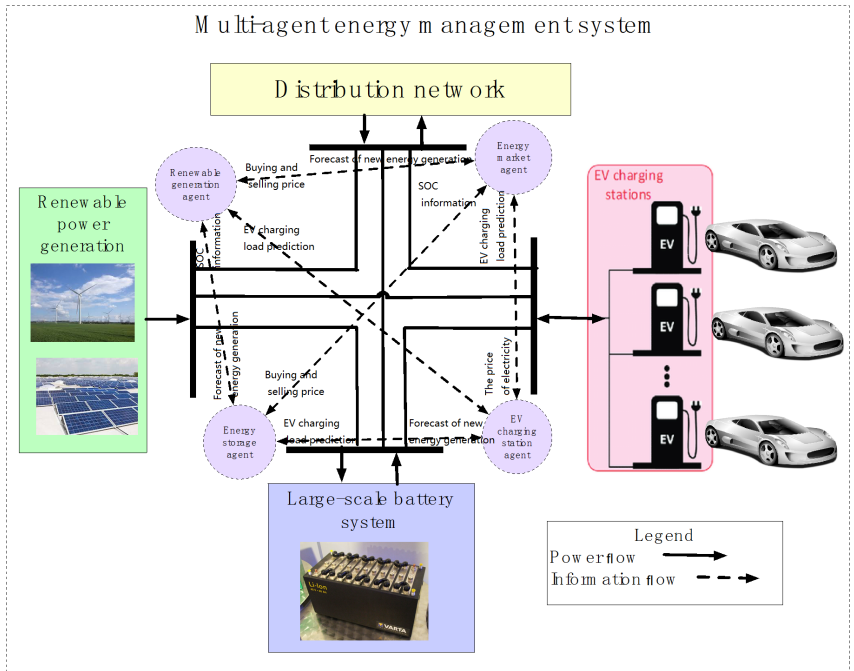

Fig. 4 A data-driven framework for optimal distribution network operation with rapid charging infrastructure and large-scale battery storage

Fig. 4 presents the basic components of the distribution network with EV charging stations, renewable power generation including wind and solar, and large-scale batteries energy system. The framework employs the following methodology: consider the distribution network operator to be large-scale batteries system owner, the dual objective for the multi-agent energy management system includes 1) minimizing the voltage deviation of the distribution network due to rapid charging and intermittent renewable generation; 2) minimizing the operation cost of distribution network. The distribution network can charge the large-scale batteries during off-peak hours and provide electricity to charging stations during high and rapid charging demand. Local renewable power generation can be used to meet the local charging demand, to be stored in battery storage, or to export to the grid.

Bi-directional power flows will occur as the state of the system changes. Four agents are identified in the system to simulate the actions and interactions of autonomous agents, based on the perceived information. Distribution network operators distribute electricity produced by electricity supplier to EV charging stations. Electricity suppliers provide time-of-use tariffs to distribution network operators. Renewable energy generation feeds electricity into the distribution network and provides the distribution network operator with the predicted generation power for the next moment. EV charging stations take electricity from the distribution network and provide a predicted load. Large-scale batteries provide the state of charge (SOC) information to the distribution network. With this information, distribution network operators schedule largescale batteries. Economic dispatch is carried out under the condition of satisfying the safe power supply of distribution network and the demand of EV charging station.

The optimal operation of large-scale batteries is achieved with reinforcement-learning (RL). Different from conventional optimization methods, RL presents excellent decision-making capability in the absence of initial environment information. The deployment of RL in decision-makings has considerable merits. Firstly, RL seeks the optimal actions by interacting with the environment so it has no requirement for initial knowledge, which may be difficult to acquire in practice. All agents act according to their own state. The environment changes in response to the actions of each agent, which is reflected in the states observed by the agent. At the same time, the environment will give rewards to the actions of each agent, which reflects the good or bad of the actions to the environment. The actions, states, and rewards are stored for the next training session. Secondly, RL can be flexibly employed to different application by off-line training and on-line implementation, considering relative uncertainties autonomously. The training process is to update each agent's table with the information saved in the previous step. Each agent uses this chart to observe the current state and determine the next action. Thirdly, RL is easier to implement in real-life scenarios as compared with conventional optimization methods. RL can obtain the optimal results with a look-up table and gives high computational efficiency. RL has been successfully applied to tackle complex energy management systems in the residential sector [26].

\section{B. EV Charging Features}

EV charging has the challenge with spatial and temporal uncertainties. The uncertainty is mainly contributed by the charging behavior of EV drivers [27]. The charging point charges the battery at different rates. There are two main charging methods, AC charging and DC charging. As described in [28], the power capacity for different charging options are as follows: $\mathrm{AC}$ charging has $\mathrm{AC}$ slow charging with rated power to be less than $11 \mathrm{~kW}$. AC fast charging is between $11 \mathrm{~kW}$ and $22 \mathrm{~kW}$. AC rapid charging is between $22 \mathrm{~kW}$ and $43 \mathrm{~kW}$. DC fast charging is $50 \mathrm{~kW}$. DC rapid charging is $150 \mathrm{~kW}$. DC ultra-fast charging is $350 \mathrm{~kW}$.

The amount of power and energy used for charging EV is generally uncertain. The paper [29] proposed a method to predict the load curve of EVs. The annual mileage data were obtained from the government or other data agencies. Travel data and driving cycles can be used to predict $\mathrm{EV}$ charging, considering that the use of EVs will not change significantly from fossil-fuel based vehicles [30]. To manage the power balance in the distribution network, demand side management can be used to incentivize drivers to provide additional management options [31]. Ref. [32] proposed that the distribution network can accommodate more EVs charging by using three-phase equilibrium. The equilibrium by matching grid dispatch with the demand side can delay the time for grid expansion. Ref. [33] proposed a dynamic pricing strategy for demand-side management. The results 
This article has been accepted for publication in a future issue of this conference proceeidngs, but has not been fully edited. Content may change prior to final publication. Citation information: DOI10.1109/CPE-POWERENG50821.2021.9501197, 2021 IEEE 15th International Conference on Compatibility, Power Electronics and Power Engineering (CPE-POWERENG)

show that it has economic and technical benefits to the power grid and users. Ref. [34] proposed an intelligent dispatch method for distribution network EV charging. Intelligent charging can reduce the adverse impact of disordered charging of EVs on power grid. All of the above approaches manage EV charging from the demand side, but this approach relies heavily on EV users. Because of the dependence on consumers, the safe operation of the distribution network will be at risk. Next, a method of using large-scale batteries to ensure the safe and stable operation of distribution network is introduced. This approach relies less on driver's participation to achieve a safe and economic power system.

\section{Energy Arbitrage for Large-scale Batteries}

Distribution networks may increase the power capacity of the generators, distribution lines and feeders to meet the large power demand variations and magnitudes. As battery technology advances and prices fall, it is possible to use large-scale energy-storage batteries to solve this problem [35]. As large-scale battery can provide extra power and energy capacity to the network, the installation will effectively delay and can possibly prevent the time of distribution network equipment upgrade. The challenge is with the scheduling of large-scale batteries, which also requires load prediction. The prediction accuracy of load patterns is higher when no EV is connected to the grid. Using the above method to predict the EV charging load, plus the conventional load, the total load can be obtained. When the predicted load exceeds the power rating of the distribution network, the excess will be provided by largescale batteries. The energy reserve in energy storage system needs to be determined. The amount is the predicted maximum power minus the available power from distribution network. Both the amount of maximum power and energy to be reserved for energy storage system needs to be determined. Calculating the required energy storage capacity is also relatively simple. As long as the area that the predicted load curve is larger than the power that the distribution network can provide is calculated, the energy that needs to be reserved can be obtained. When the energy storage system reserves enough power and electric energy, this ensures the safe operation of the power grid. The remaining part of the energy storage capacity can obtain maximum benefits under the guidance of the time-of-use price. Each charge and discharge of a battery will affect the storage capacity of the battery. The cost of battery degradation is taken into account in calculating the maximum benefit that energy storage can get from buying power at a low price and selling it at a high price. The addition of large-scale batteries in the distribution network can also reduce the distribution loss of the network. $F_{\text {loss }}$ is the income of the energy loss reduced after energy storage is added to the grid. It can be calculated with (10). $F_{\text {loss } 1}$ is the cost of the loss of power grid without adding energy storage, and $F_{\text {loss } 2}$ is the cost of the loss of power grid after adding energy storage. Arbitrage income $F_{a}$ can be calculated by the following equations:

$$
\begin{gathered}
F_{a}=F_{\text {sale }}-F_{\text {buy }} \\
F_{\text {sale }}=\sum_{t=1}^{T} \operatorname{TOU}(t) P_{\text {dis }}(t) \Delta t
\end{gathered}
$$

$$
\begin{gathered}
F_{\text {buy }}=\sum_{t=1}^{T} \operatorname{TOU}(t) P_{c}(t) \Delta t \\
F_{\text {loss }}=F_{\text {loss } 1}-F_{\text {loss } 2}
\end{gathered}
$$

Where, $F_{\text {sale }}$ is the income received from selling electricity stored in the battery to the grid. $F_{b u y}$ is the cost of electricity purchased from the grid to be stored in the battery. TOU $(t)$ is the time-of-use price of electricity suppliers in Table I. $P_{d i s}$ and $P_{c}$ are discharging power and charging power of the large-scale batteries. $T$ is the time of day.

In order to determine the SOC of a large-scale battery, Ref. [36] presented a method for calculating SOC is presented. The SOC calculation model of large-scale battery is shown in (11)-(12). Considering that the degradation of battery will have an impact on the economic scheduling strategy. Ref. [37] presented using the rainflow-counting algorithm as the basis for an ex-post benchmark method for assessing battery cycle life (13).

$$
\begin{gathered}
Q_{0}=\int_{0}^{\infty} I_{d}(t) d t \\
\operatorname{SOC}(t)=1-\frac{\int_{0}^{t} I_{d}(t) d t}{Q_{0}} \\
L=\sum_{i=1}^{I} \Phi\left(\sigma_{i}\right)
\end{gathered}
$$

Where, $Q_{0}$ is the total charge of the battery that can be stored in or maximum capacity of the battery. $I_{d}$ is the discharging current. $\int_{0}^{t} I_{d} d t$ is the charge delivered from the battery. The total life loss $L$ from SOC profile is assumed to be the sum of the life loss from all $I$ number of cycles identified by the rainflow-counting algorithm. $\Phi(\sigma)$ is the cycle depth stress function. $\sigma$ is the cycle of depth.

\section{CONCLUSION}

This paper introduces the current state of the EV markets in China and the UK. There is a need to better manage the power flows in smart grids and the distribution networks to ensure EV demands are met. Large-scale energy storage including battery is a feasible solution to provide additional regional power and energy capacities. This paper describes a data-driven framework for managing the charging demand for EVs with large-scale battery. In the next step, the authors will implement the design of the data-driven framework. Methods to forecast the load of EVs and renewable power generation will also be developed. Previous historical data can be used to train the neural network, and then use the trained neural network to obtain the predicted value, for example, the charging load prediction of EVs. For the historical data of EV charging stations in the past, data related to charging load can be found as the input of the 
This article has been accepted for publication in a future issue of this conference proceeidngs, but has not been fully edited. Content may change prior to final publication. Citation information: DOI10.1109/CPE-POWERENG50821.2021.9501197, 2021 IEEE 15th International Conference on Compatibility, Power Electronics and Power Engineering (CPE-POWERENG)

neural network and the load as the output for training. Battery degradation should be taken into account when building a data-driven model for distribution networks. Having large-scale batteries not only ensures the safety and stability of the system during normal operation, but also serves as a backup power source for important equipment when necessary. The charging demand of a large number of EVs will have a negative impact on the distribution network. The traditional way is to upgrade the distribution network equipment to increase the power supply capacity. In this paper, the problem of insufficient power supply during peak demand can be solved by connecting large-scale batteries to distribution network. It is foreseeable that a safe, marketable, affordable, renewable way of travel for both the $\mathrm{UK}$ and China is possible in the near future.

\section{ACKNOWLEDGEMENTS}

This work is sponsored by EPSRC DTE Network+; Brunel University London BRIEF Funding; Department of Finance and Education of Guangdong Province 2016 [202]: Key Discipline Construction Program, China; the Education Department of Guangdong Province: New and Integrated Energy System Theory and Technology Research Group [Project Number 2016KCXTD022].

\section{REFERENCES}

[1] J. de Hoog, T. Alpcan, M. Brazil, D. A. Thomas and I. Mareels, "Optimal Charging of Electric Vehicles Taking Distribution Network Constraints Into Account," IEEE Transactions on Power Systems, vol. 30, pp. 365-375, Jan. 2015.

[2] K. Chaudhari, N. K. Kandasamy, A. Krishnan, A. Ukil, and H. B. Gooi, "Agent-based aggregated behavior modeling for electric vehicle charging load," IEEE Transactions on Industrial Informatics, vol. 15, pp. 856-868, Feb. 2019.

[3] X. Cheng et al., "Dispatch of electric vehicles to participate in new energy consumption strategies," 2018 2nd IEEE Conference on Energy Internet and Energy System Integration (EI2), Beijing, pp. 16, 2018.

[4] D. Li, A. Zouma, J. T. Liao, and H. T. Yang, "An energy management strategy with renewable energy and energy storage system for a large electric vehicle charging station," eTransportation, vol. 6, p.100076 Nov. 2020.

[5] S. Deb et al., "Charging coordination of plug-in electric vehicle for congestion management in distribution system integrated with renewable energy sources," IEEE Transactions on Industry Applications, vol. 56, pp. 5452-5462, Sep. 2020.

[6] IEA, "Global electric car sales by key markets," 2010-2020. [Online]. Available: https://www.iea.org/data-andstatistics/charts/global-electric-car-sales-by-key-markets-20152020

[7] CNPC, "China,the world's largest oil importer," Jun.2018. [Online]. Available: http://www.cnpc.com.cn/syzs/sysh/201808/0be99ca106634c069f2c $\underline{412 \mathrm{ead} 87 \mathrm{db} 11 . \mathrm{shtml}}$

[8] UN, "Electric vehicles in the context of sustainable development in China," May. 2011. [Online]. Available: https://www.un.org/esa/dsd/resources/res pdfs/csd19/Background-Paper-9-China.pdf

[9] TSINGHUA-EIRI, "China Southern Power Grid Electric Vehicle Service Co., Ltd. signed a cooperation agreement with Sichuan Energy Internet Research Institute of Tsinghua University," Jun.2020. [Online]. Available: http://www.tsinghuaeiri.org/news/newsdetail.html?id=159

[10] ICET, "Updated timetable for phasing out China's traditional ICE vehicles and its environmental benefits assessment," Aug.2020. [Online].

Available: http://www.icet.org.cn/admin/upload/2020072372032769.pdf

[11] CPSDNA, "Research report on the ecological development of smart car network of State Grid," Dec.2017. [Online]. Available: http://www.cpsdna.com/article-1129.html
[12] SGCC, "The State Grid Corporation of China has built charging piles," 2020. [Online]. Available: http://www.sgcc.com.cn/

[13] IEA, "Private electric vehicle slow chargers by country," 2019. [Online]. Available: https://www.iea.org/data-andstatistics/charts/private-electric-vehicle-slow-chargers-by-country2019

[14] IEA,"Publicly accessible electric vehicle fast chargers by country,"2019.[Online]. Available: https://www.iea.org/data-andstatistics/charts/publicly-accessible-electric-vehicle-fast-chargersby-country-2019

[15] IEA, "Promoting vehicle efficiency and electrification through stimulus packages," 2020. [Online]. Available: https://www.iea.org/articles/promoting-vehicle-efficiency-andelectrification-through-stimulus-packages

[16] GOV.UK, "Low-emission vehicles eligible for a plug-in grant" 2020. [Online]. Available: https://www.gov.uk/plug-in-car-van-grants

[17] ZAP-MAP, "EV charging stats 2021," 2021. [Online]. Available: https://www.zap-map.com/statistics/

[18] Office for Low Emission Vehicles. " Lessons learnt from the plugged-in places projects," 2013. [Online]. Available: https://assets.publishing.service.gov.uk/government/uploads/syste m/uploads/attachment data/file/236750/plugged-in-places-lessonslearnt.pdf

[19] Office for Low Emission Vehicles, "Grant schemes for electric vehicle charging infrastructure," 2016. [Online].Available:https://www.gov.uk/government/organisations/ office-for-low-emission-vehicles

[20] ZAP-MAP, "EV energy tariffs," Nov. 2020. [Online]. Available: https://www.zap-map.com/charge-points/ev-energy-tariffs/

[21] SGCC, "Scheduling operation aspect," 2019. [Online]. Available: http://www.sgcc.com.cn/html/sgcc main/col2017041274/column 2017041274 1.shtml?childColumnId=2017041274

[22] S. Küfeoğlu and M. G. Pollitt, "The impact of PVs and EVs on domestic electricity network charges: A case study from Great Britain," Energy Policy, vol. 127, pp. 412-424, Apr. 2019.

[23] K. Feng, Y. Zhong, B. Hong, X. Wu, C. S. Lai and C. Bai, "The impact of plug-in electric vehicles on distribution network," 2020 IEEE International Smart Cities Conference (ISC2), Piscataway, NJ, USA, pp. 1-7, 2020.

[24] C. Li, H. Zhou, J. Li, and Z. Dong, "Economic dispatching strategy of distributed energy storage for deferring substation expansion in the distribution network with distributed generation and electric vehicle," Journal of Cleaner Production, vol. 253, p.119862, Apr. 2020.

[25] UKPN, "Energy storage contribution to security of supply," Dec.2016. [Online]. Available: https://innovation.ukpowernetworks.co.uk/wpcontent/uploads/2019/09/SDRC9.6-Energy-Storage-Contributionto-Security-of-Supply.pdf

[26] X. Xu et al., "A multi-agent reinforcement learning-based datadriven method for home energy management," IEEE Transactions on Smart Grid, vol. 11, pp. 3201-3211, Jul. 2020.

[27] Z. Huang et al., "A novel power market mechanism based on blockchain for electric vehicle charging stations," Electronics (Switzerland), vol. 10, pp. 1-21, 2021.

[28] Deloitte, “energy-resources/deloitte uk electric vechicles WEB,"2019. [Online]. Available: https://www2.deloitte.com/content/dam/Deloitte/uk/Documents/en ergy-resources/deloitte-uk-electric-vechicles-WEB.pdf

[29] Q. Hu, H. Li, and S. Bu, "The prediction of electric vehicles load profiles considering stochastic charging and discharging behavior and their impact assessment on a real UK distribution network," in Energy Procedia, vol. 158, pp. 6458-6465, 2019.

[30] N. H. Tehrani and P. Wang, "Probabilistic estimation of plug-in electric vehicles charging load profile," Electric Power Systems Research, vol. 124, pp. 133-143, 2015.

[31] S. Davarzani, I. Pisica, G. A. Taylor, and K. J. Munisami, "Residential demand response strategies and applications in active distribution network management," Renewable and Sustainable Energy Reviews, vol. 138, pp.110567, Mar. 2021.

[32] J. de Hoog, T. Alpcan, M. Brazil, D. A. Thomas, and I. Mareels, "Optimal charging of electric vehicles taking distribution network 
constraints into account," IEEE Transactions on Power Systems, vol. 30, pp. 365-375, Mar. 2015.

[33] A. Abaza and A. M. Azmy, "Demand-side management-based dynamic pricing within smart grid environment," in 2013 IEEE International Conference on Smart Energy Grid Engineering (SEGE), pp. 1-6, 2013.

[34] A. S. bin Humayd and K. Bhattacharya, "Design of optimal incentives for smart charging considering utility-customer interactions and distribution systems impact," IEEE Transactions on Smart Grid, vol. 10, pp. 1521-1531, Mar. 2019.

[35] C. S. Lai and G. Locatelli, "Are energy policies for supporting lowcarbon power generation killing energy storage?" Journal of Cleaner Production, vol. 280, pp. 124626, Jan. 2021.

[36] M. I. Wahyuddin, P. S. Priambodo and H. Sudibyo, "State of charge (SoC) analysis and modeling battery discharging parameters," 2018 4th International Conference on Science and Technology (ICST), Yogyakarta, pp. 1-5, 2018.

[37] B. Xu, J. Zhao, T. Zheng, E. Litvinov and D. S. Kirschen, "Factoring the cycle aging cost of batteries participating in electricity markets," IEEE Transactions on Power Systems, vol. 33, pp. 2248-2259, March 2018. 